\title{
Culture, Literature and the Contradictions of Socialist Capitalism in Chinese Corporate Magazines
}

Accepted version of paper subsequently published in Asian Studies Review, vol.34.1 (March 2010): 41-61.

Colin Hawes

University of Technology Sydney

\section{1: Introduction}

An interesting cultural phenomenon has emerged in China over the past decade. Along with the restructuring of Chinese state-owned enterprises into shareholding corporations and the growth of privately-managed corporations within the gaps left by the state sector has come a fixation on the concept of "corporate culture" (qiye wenhua). Elsewhere, I have shown how Chinese conceptions of corporate culture differ markedly from their, mainly American, models, especially in their greater focus on socialist ideals and traditional Chinese cultural values (Hawes 2008). In this paper, I will analyze one central vehicle through which corporate culture-building, Chinese-style, or the inculcation of "positive" cultural values among employees, takes place within large Chinese corporations and corporate groups. This vehicle is the corporate magazine, or online forum on the corporation's website.

My survey of the websites of 300 large Chinese corporations found that approximately $44 \%$ publish one or more in-house magazines on their websites, and several others refer to in-house magazines that are not available online. These figures almost certainly understate the number of magazines, as most of the largest Chinese firms are corporate 
groups, and the survey only looked at the parent companies of these groups. Many of their subsidiary companies also publish in-house magazines. ${ }^{1}$ Considering the fact that most of these corporations employ tens or even hundreds of thousands of employees, their magazines potentially have a powerful impact on their corporate readership.

So what kinds of values and "culture" do these corporate magazines propagate? And why do corporate managers channel so many resources into publishing these magazines and getting employees to contribute to them? What does the corporate magazine phenomenon tell us about the distinctive, and sometimes self-contradictory, cultural values of large Chinese corporations today? After giving examples of the different categories of content and creative work found in the magazines of several large Chinese corporations, I will address the above questions and place the corporate magazine phenomenon within the broader context of Chinese conceptions of corporate culture and the social function of corporations.

Of course, China did have large industrial organizations prior to the re-introduction of the corporate form in the reform period. ${ }^{2}$ During the high Communist period (1949-77) and well into the 1980s, the vast majority of these organizations were state-owned enterprises or factories. Many of these enterprises also published their own in-house newspapers,

\footnotetext{
${ }^{1}$ For example, China Mobile, one of the largest wireless service providers in China, does not have a magazine on its website, but in my interview with one of the firm's Beijing subsidiaries in June 2008, the manager told me that each of the firm's thirty one provincial subsidiaries publishes at least one in-house magazine, and some publish two or three!

2 The first People's Republic of China [PRC] Company Law was promulgated in 1993, but prototypes of the corporate form, i.e. firms that gave limited liability to their investors, had existed in Communist China since the late-1970s, and corporate legal structures had also been adopted much earlier during the Republican period (1911-1949) and even as early as the late-Qing. See Liu 1998, 7-11; and for more details, Kirby 1995, 43-63.
} 
which focused largely on socialist propaganda and exhortations to employees to work assiduously for the Party cause. ${ }^{3}$ While today the vast majority of these state-owned enterprises have been restructured into corporations or corporate groups, and even those that still maintain majority state ownership are supposed to "separate themselves from politics" and focus on making a profit, some of the attitudes and writing style of the Communist-period enterprise newspapers still appear in contemporary corporate magazines, alongside the management-speak and financial jargon that are common to corporate magazines the world over. Surprisingly, this distinctive juxtaposition of socialist and capitalist ideals is not restricted to state-controlled corporations, but also appears in the magazines of many privately-managed corporations.

Even prior to the Communist Revolution, during the Republican period (1911-49) many Chinese joint stock companies were established under the Republican Company Code (Liu 1998, 10). In some cases, these companies also published in-house newspapers or magazines, including articles written by their employees. In a fascinating paper, Wenhsin Yeh has argued that one such company, the Bank of China, was attempting to mold the behaviour and attitudes of its employees so that they became loyal and civilized Bank of China "men". They were not merely expected to do their jobs, but to view their positions as an opportunity for Neo-Confucian-style self-realization and cultivation, and to view the corporation as their extended family (Yeh 1995, 106-7). The Bank embraced a kind of "enlightened paternalism ... that simultaneously stressed the universal applicability of modern professional expertise and the timeless validity of certain

\footnotetext{
${ }^{3}$ For example, the Shougang Group, a major iron and steel conglomerate based in Beijing, has published its Shougang Daily since 1953. The publication currently has a circulation of 35,000, plus an online edition. See Shougang Group n.d.(a).
} 
Confucian ethical norms" (Yeh 1995, 111). The Bank's in-house newsletter, titled Life in the Bank of China, encouraged its employees to contribute articles on their working experiences, and to express their opinions on how to improve the Bank's management. Some of these articles are surprisingly forthright in their criticisms. One employee declared that working in the Bank was "monotonous and mechanical," and that "one loses interest in all things. Only numbness is felt. A restlessness grips us all" (Yeh 1995, 112-14, esp.114 n55).

The existence of such corporate magazines in the Republican period - and their intended socializing functions - suggests that contemporary Chinese corporations are tapping into a deeper cultural tendency to view the employer-employee relationship as a social and educational one rather than just as an economic contract. I will discuss this point further in my conclusion.

When we turn to Chinese corporate magazines today, there is an embarrassment of riches to study, so my choice of case studies will inevitably constitute only a small fraction of the available materials. I have selected from the typical categories of articles that regularly appear in the magazines of China's largest 500 corporations. I focus on these larger corporations because they tend to have more resources to support their publications and to spend on developing a distinctive corporate culture. Their magazines are also much more widely available, generally published on their websites. This means that my conclusions may not be so directly relevant to smaller Chinese corporations, whose culture will generally be strongly influenced by their individual CEO or founder. 
Among the larger corporations, I have selected from a range of industrial sectors, and have roughly balanced the number of state-controlled and privately-managed corporations, in order to show that there are some common features of these magazines that transcend industry type and ownership structure. At the same time, each individual corporation has its own complex character, and so I have randomly selected one firm, China Datang Corporation, for more detailed examination, to demonstrate that the values expressed within a single corporation's publications can sometimes be contradictory and may reflect differences among various power groups within the firm. In terms of time range, I have focused on articles published since 2005.

\section{Typical Forms and Content of Chinese Corporate Magazines}

There are two basic formats in which contemporary Chinese corporate magazines are published. One is as a monthly (or weekly) glossy paper magazine, which may also be posted in full on the firm's website. The other format is more like an online blog, in other words, a series of open-ended online columns on different themes, which can be updated whenever new articles are available, sometimes daily. In most cases, it appears that whatever the format, articles must first go through an editorial process before being published. ${ }^{4}$ The titles of these magazines tend to be quite similar, frequently consisting of the corporation's name followed by “people” (ren) - for example Huawei People, or Tianzheng People. Others use the words "weekly" or "monthly" instead, as in Vanke

\footnotetext{
${ }^{4}$ Some websites have an e-mail address for submissions to the magazine, as with the Sinopec Group's Sinopec News (Sinopec Group n.d.(a)); or the Tongwei Group's Tongwei Lifestyle magazine (Tongwei Group n.d.). Others post Calls for Submission of Manuscripts, with the contact details of the editorial committee, as with China Datang's Stories of Dedication, discussed below.
} 
Weekly or "lifestyle", as in Tongwei Lifestyle. Some corporations have a separate newspaper (bao), which focuses mainly on company and industry news, along with some government policy announcements, whereas their magazine focuses more on more discursive and creative work, along with management theory articles. ${ }^{5}$ But other corporations combine everything into one publication.

In terms of content, we can identify four main sections that appear, with slight variations, in the great majority of corporate magazines. For those corporations that don't publish a separate newspaper, there is normally a section on the latest company news, including new projects, successful business ventures, honours won by the firm or its managers and employees, and other positive achievements that place the firm in a good light. This section is little different from corporate magazines the world over, and has little interest for readers outside the corporation - possibly for those within the corporation too - so I will not give any detailed examples here.

The second kind of content found in these corporate magazines is the management forum, in other words, articles on management theory, sales techniques, and how-to articles on doing business in different situations and environments. While articles like this are also a staple of corporate magazines worldwide, I have included some examples below to provide a counterweight to the lofty cultural reflections, creative writing, and socialiststyle rhetoric that follow. Indeed, from the standpoint of Anglo-American shareholderprimacy corporate theory, there appears to be a clear contradiction between the market-

\footnotetext{
${ }^{5}$ See, for example, the difference between the Zhengtai Group's Zhengtai News and Zhengtai Magazine (Zhengtai Group, n.d.)
} 
oriented, profit-seeking attitude of the management forums and the demands for disinterested self-sacrifice, or alternatively, the aspirations for cultural self-realization, that appear elsewhere in these magazines. ${ }^{6}$

The third kind of content is the cultural forum, which generally includes creative work by employees in a wide range of forms and genres. Lyrical prose pieces, "chicken soup for the soul"-style inspirational pieces, free verse and employee photography are all common, but surprisingly, so are traditional forms such as classical poetry, calligraphy and traditional Chinese painting. Some of these contributions are loosely or directly related to the corporation's business - some "poems," for example, are merely doggerel verses celebrating the "joys" of working for this wonderful corporation, obviously designed to give the poet-employee brownie points with corporate management. But as I will demonstrate, quite a number of these cultural pieces bear no obvious relationship to corporate life at all - except perhaps in a negative sense when they complain of the strains and stresses of work - and they would not look out of place in a mainstream creative writing or art magazine.

The fourth kind of content is the exemplary employees or "corporate stars" section of the magazine. This section usually includes heartwarming - or sometimes heartrending stories of employees going the extra mile for customers, or demonstrating their selfless dedication to the corporation above everything else, or generally behaving in an upstanding way to give the corporation a good reputation in society. Though certainly

\footnotetext{
${ }^{6}$ For discussion of shareholder primacy theory and other theories of the corporation, see Tomasic et al 2002, section 2.8.
} 
many non-Chinese corporations also publicly celebrate the achievements of their employees, the unrelenting focus on values of self-sacrifice and group solidarity in these stories of Chinese employees inevitably brings to mind Communist-era model workers such as Lei Feng and the heroes of the Daqing Oilfields (Landsberger 1995, 24-8). Often the line between serving the corporation and serving China are deliberately blurred in these stories to give the impression that the employees' contributions go far beyond simply maximizing the firm's profits and providing a return to its shareholders, and are actually of national importance in helping China become a strong and powerful nation once more.

There are slight variations on these four kinds of content in some magazines, but there is a general similarity in format and content categories over a wide range of industry sectors and ownership types. There appear to be some common ideas among Chinese corporate managers as to the cultural functions and purposes of in-house magazines or online forums. At the same time, emerging from these magazines are some contradictions between the values of different corporations, and even contradictory values within a single corporation. I will now demonstrate these features by giving some detailed examples from each content category.

\section{How to be a Good Manager: Practical Tips from Chinese Corporate Magazines Cosun Group (Qiaoxing jituan), based in Huizhou, Guangdong Province, is one of the largest privately-managed corporations in China. Its business focuses on producing}


telephones and other telecommunications equipment (Cosun Group n.d.(b)). ${ }^{7}$ Its corporate magazine, Cosun People, includes a section in which employee contributors publish articles on their insights into management and leadership (Cosun Group n.d.(a)). One article from a recent issue is entitled "Empty Out That Piece of Grit" (Anon. 2007a). In it, the author recounts a recent hiking trip up a mountain with some friends, in which they are competing to try and reach the summit first. Not far from the top, he feels a piece of grit in his shoe, but he decides not to stop and empty it out, in case he loses time. After a few minutes the grit causes a blister to form and then burst on his foot, and this causes him so much pain that he can no longer walk. Far from winning the race, he suffers the humiliation of being carried to the summit in last place. Reflecting on this nasty experience, he draws parallels with managing a corporation:

Actually management work is like this too: managers normally think that looking at the big picture and ignoring the petty details is a more efficient way of working. But it could be that when one neglects small problems they have a tendency to develop, and these small problems turn into major issues, and ultimately lead to the failure of management work (Anon. 2007a).

The author then gives two real-life examples of how small problems led to major issues within the corporate context. The first involves a regional manager called Zhang who supervised several sales representatives. One of these, called Zhou, was very good at meeting sales targets, but had a "small flaw," which was that he never missed an

\footnotetext{
${ }^{7}$ According to its website profile, the firm is now seeking to diversify into internet products and the mining industry, which seems an unusual combination. In 2005, Cosun was ranked at number 23 in size of assets among Chinese privately-managed enterprises. See Minying jingji xinxiwang 2005.
} 
opportunity to get something for free. Manager Zhang ignored this, as he thought Zhou was doing his job well, but when Zhou came to ask for a salary raise, Zhang told him he had no authority to decide employee salaries. Two days later, Zhou resigned and went over to a competing firm, taking many of the firm's clients with him. It turned out that the competing firm had regularly invited Zhou for "free" meals, taking advantage of his character flaw, and in this way they had convinced him to jump ship. The second example describes one of the author's clients, another firm, which discovered a few defective samples within a large shipment of their product just before it was due to be sent out. Rather than delay the shipment to sort out the quality problems, they assumed that the client would not notice one or two substandard products in such a large batch. In the end, the client not only discovered the defective products, but as a result decided not to purchase from the firm again. The author concludes: "If we are able to analyze such issues carefully, even if it means spending some time sorting out small problems, it will save a lot more effort trying to deal with much larger problems later on."

One could easily object to the author's argument here as too simplistic. For example, it may lead to a kind of unhealthy micro-control, where managers become so stressed about small details that they discourage employees from making any decisions on their own. This is perhaps even more likely to lead to employees "jumping ship," or at least simmering with quiet resentment. Likewise, the author doesn't explain how Zhang, the regional manager, could have solved the problem with the freeloader Zhou. Could he have prevented Zhou from privately accepting meal invitations from the competition? But despite its shortcomings, at least the article makes a clear point using a vivid analogy 
from daily life (grit in one's shoe), and it may have stimulated reflection and discussion among Cosun's managerial staff.

Cosun's forum avoids use of technical jargon and managerial theory, while at the same time focusing squarely on practical tips to improve managers' skills. Some firms' management forums tend towards a more jargon-filled, even academic, approach, whereas others go to the opposite extreme, searching for tips on management from traditional Chinese cultural texts. At the technical end of the scale, the corporate magazine of COFCO Group (Zhongliang jituan), an agricultural and food products conglomerate, contains two regular forums entitled "Seminar" and "Academy," each with three or four reflective articles that would not look out of place in a scholarly management theory journal. The only feature they lack is footnotes (COFCO Group n.d.(a) and (b)). ${ }^{8}$ To give a brief example, the February 2008 issue includes an article on marketing management that describes how the author's marketing unit within COFCO's cold drink subsidiary has successfully introduced the concepts of "key performance indicators" (KPIs) and transparent management. As the author states: "We have taken each link of the [marketing and sales] process and made it into a measurable KPI, so assessment of how work is done is no longer dependent on subjective feelings, but is based on measuring each KPI" (Zheng 2008).

\footnotetext{
${ }^{8}$ The Group also manufactures biological, chemical and packaging products, and is engaged in real estate and finance too.
} 
Clearly, the attempt to portray management as an objective science by introducing impenetrable acronyms and meaningless statistics has made its way into some circles of China's corporate leadership.

At the other end of the scale, some Chinese corporate magazines publish articles that relate the practice of management to traditional Chinese philosophy and values. Though certainly more interesting to read than the KPI genre, these articles occasionally seem a little far-fetched in their interpretations. For example, Huawei People, the magazine of Huawei Technologies, China's most successful communications technology firm, published an article in August 2006 entitled "Management through Zen Enlightenment" (Huawei Technologies 2006a). The article describes a regular cultural seminar for Huawei's employees held over the previous year, during which the employees engaged in guided study sessions of an eclectic variety of cultural, historical and management texts. The article then focuses on one session, where ancient Chinese Zen stories were introduced and Huawei's employees attempted to apply them to their work lives. The following Zen Buddhist joke is representative:

Four monks decide to meditate for seven days in a row. During that time, none of them is allowed to talk. No-one makes a sound for the whole first day, but during the night the only lamp in the room sputters and goes out. The first monk can't help himself, and shouts: 'Oh no! The light's gone out!' The second monk replies: 'Be quiet: we're not supposed to say anything!' The third monk says: 'Well if we're not 
supposed to talk, what are you doing?' And the fourth monk laughs and says: 'Ha! I'm the only one who hasn't talked yet ...!' (Huawei Technologies 2006a)

There are two possible readings of this text, according to Huawei's employees. One interpretation is that, if we blame other people, it is very likely that we are also to blame ourselves. In other words, if everyone corrects their own mistakes instead of trying to pass the buck, the corporation will operate much more efficiently. The other interpretation is that if the corporate culture does not encourage employees to talk to their colleagues in order to resolve problems - but instead everyone stays silently working in their offices like Buddhist monks adopting a vow of silence - it will not lead to a successful and profitable firm.

Though this article is entitled "Management through Zen Enlightenment," the employees' cultural seminar that it describes clearly has two overlapping functions: (i) to apply traditional Chinese (and some foreign) cultural texts to the contemporary business and work environment; and (ii) to provide employees with a broader education in the humanities. The article approvingly quotes employees praising the seminars because they "opened up new perspectives, helped them control their impulsive tendencies, gave them ideas to apply in their work, and allowed them to have spiritual exchanges with their workmates" (Huawei Technologies 2006a). Hence there is an overlap in some of these magazine articles between practical business/management training and cultural improvement, as if such cultural improvement of employees is actually a major aim of corporate management. It is interesting to see this attitude expressed even in the 
magazine of Huawei Technologies, one of China's most profitable and ruthlessly competitive privately-managed hi-tech corporations. ${ }^{9}$

Further evidence for the importance of cultural improvement among corporate employees is provided by the next category of magazine content, namely, creative work by employees.

\section{Displaying the Creative Work of Employees in Corporate Magazines and on Corporate Websites}

Those corporations that produce a hard-copy magazine generally include around five to ten pieces of creative writing by employees in each issue, and some also publish employees' artwork, calligraphy or photography too. Corporations that prefer the online blog format may post such creative work even more frequently. It appears that there is a real thirst for creative expression among Chinese corporate employees!

For example, China Datang Corporation, one of the largest state-controlled electricity providers in China, has a creative writing forum on its website called "Literary Garden of Tang Writings" (China Datang n.d.(b)). ${ }^{10}$ Over the past three years this forum has published approximately three hundred lyrical prose pieces and poems by employees, averaging around two contributions per week. The quality of these pieces suggests that

\footnotetext{
${ }^{9}$ Huawei is famous for promoting a "wolf culture" among its employees, in other words, giving financial incentives for them to work in a pack to sniff out the competition and destroy it. See Wang 2007, and further discussion in the section on exemplary employees below.

${ }^{10}$ Tang here refers to the corporation's name Datang, literally Great Tang, but inevitably also conjures up associations of the cultural achievements of the Tang dynasty (618-907).
} 
they have been selected from a much larger pool of submissions. The vast majority of these works bear no obvious relation to the business of the corporation, but instead revolve around traditional Chinese lyric themes such as travel records, reflections on visiting historical sites, melancholy poems about lost love, vaguely inspirational pieces on overcoming life's difficulties, appreciations of the small details of daily life, and tearjerking recollections of mother's love or missing home.

To give an example of the less mawkish pieces, a prose piece entitled "Autumn Leaves" by Gao Kai, of the Datang Nanjing Xiaguan Power Station, begins with a reflection on peoples' contrasting reactions to the coming of Autumn:

Some weep when Autumn comes, but others love the Autumn. Amidst the rustling of Autumn leaves shaken from the trees, one can hear the tragic lament of Song $\mathrm{Yu}$ bewailing the collapse of the ancient Kingdom of Yue. ${ }^{11}$ Yet one also recalls the couplet: 'Everyone else says that Autumn is a season for tragic loneliness,/But I say Autumn days are much better than Spring mornings!, ${ }^{12}$ When the yellowing leaves fly about telling us that Autumn is here, and the sounds of wind, rain and leaves combine like noisy footsteps tramping past, I find myself more happy than sad. Deep in my heart I know that the forces of deathly cold are not killing wantonly but

\footnotetext{
${ }^{11}$ Song Yu (c. $3^{\text {rd }}$ century BC), ancient poet. The poem "Nine Changes" (jiu bian), a long melancholy meditation on the sorrow of autumn found in the Chu ci [Songs of Chu], is normally attributed to him. ${ }^{12}$ This couplet appears to be a slight variation on the famous lines of the Mid-Tang Dynasty poet Liu Yuxi, "Since ancient times, Autumn has been a season of tragedy and loneliness,/But I say that Autumn days are much better than Spring mornings." The quatrain, entitled "Qiu ci" [Autumn Lyric], continues: "In the clear sky a crane soars up, wings beating the clouds,/It draws my poetic inspiration right up to the azure heavens." Xiao et al 1983, 836.
} 
are cleansing the dust from the past season. Beneath the melancholy rustling and bleak exterior lies great beauty and new hope (Gao 2007).

The author then describes his recent visit to Nanjing Normal University - an annual pilgrimage - to view two ancient gingko trees. The branches of the trees are like coiled dragons, and the glistening yellow leaves are like shells or little ferns floating in the breeze and spreading all over the ground (Gao 2007).

The author goes on in this vein for a few more paragraphs, then concludes by returning to his initial reflection on peoples' differing reactions to the same external phenomenon:

These images of autumn always lift me out of the chaos of mundane reality into a transcendent realm of pure emptiness ... But people are already starting to sweep up the leaves with their scraping brooms, and the refuse trucks are piled high with those golden fallen leaves as if they are mere garbage ... Could it be that not everyone appreciates the joys of tramping through dense autumn leaves? I suppose the difference between garbage and treasure is mostly a matter of perspective! (Gao 2007)

It is surprising to find these transcendent sentiments on the same corporate website as discussions on how to rapidly increase electricity production and expand into one of the “top five hundred corporations in the world by 2010" (China Datang Corporation. N.d.(c)). And when the author talks about the "chaos of mundane reality," one can only 
assume he is describing his daily work at the corporation! But many Chinese corporate managers and employees seem to believe that what they would call "spiritual civilization" (jingshen wenming) and "material civilization" (wuzhi wenming) can coexist, and even mutually support each other, within a large corporation.

Of course, not all the contributions to these cultural forums are influenced by classical poetry or prose genres. Many are simply vivid human interest stories drawn from the writer's own life experience, often with a subtle or blunt moral attached. For example, one writer describes a friend who doesn't like the taste of green onions, a staple in Chinese cooking. His first wife cooked dinner for him for many years, and she never added green onions even though she quite liked the taste of them. But after he divorced his first wife and married a younger woman, his new wife refused to cook dishes without green onions, so he was forced to change his eating habits. The new wife also disliked garlic, which the husband used to eat every day and which his former wife added to almost every dish that they ate. The new wife even refused to have any garlic in the house, because she hated the smell. After a few weeks of this deprivation, the friend finally realized how much his first wife really loved him, as she was willing to give up what she liked for years just for the sake of marital harmony. The writer concludes that we often fail to appreciate the small things people do for us, because we are too intent on seeking out extravagant declarations of love, even though such declarations are often superficial (Liu 2007). 
Though the morals of these little anecdotes are usually clear, they have little obvious connection to the corporation's business. At a stretch, one might argue that writing and circulating these stories at least encourages employees to reflect on ethical questions, something that may be useful when dealing with the frequent moral ambiguities of a competitive business environment.

Many corporations also encourage their employees to publish samples of their paintings, calligraphy and photography, often in conjunction with annual employee art contests. Again, we see a range of content and subject matter in these artworks. Some are obviously intended as corporate propaganda, but others have no overt message beyond the idea that it is good for employees to hone their artistic skills, express their creativity, and develop interests that go beyond their daily work.

In the corporate propaganda vein is a selection of calligraphic prints exhibited on Haier Group's website, trumpeting the Group's latest corporate slogans, such as: ${ }^{13}$

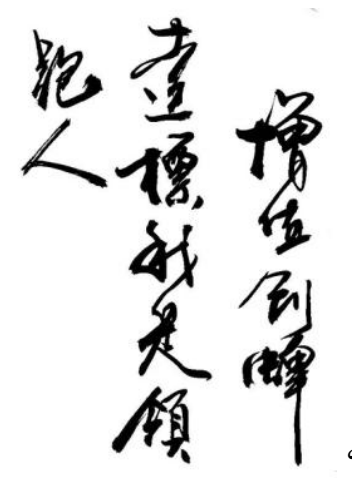

"I will be first in the race to add value and create a new brand"

\footnotetext{
${ }^{13}$ These two images were viewed by the author on Haier's website in July 2006, but have since been removed. There are some other examples of painting, calligraphy and traditional paper cuts by employees still on the website (Haier Group n.d.).
} 
"I innovate therefore I add value:

Every employee should join in creating a new brand"

Other examples of employee artwork are less clearly related to the promotion of the firm's business. The Shougang Group, a major steel and hi-tech conglomerate based in Beijing, has an extensive gallery of paintings and calligraphy by employees posted on its corporate newspaper's website, and many of the contributions have no overt promotional or moral message. At most one could say they demonstrate that Shougang's employees are remarkably talented and cultivated. The following landscape painting entitled "Floating Clouds Over Secluded Valleys," by Wang Guoshun, of Shougang International Engineering Corp. Ltd., is typical (Wang 2008): ${ }^{14}$

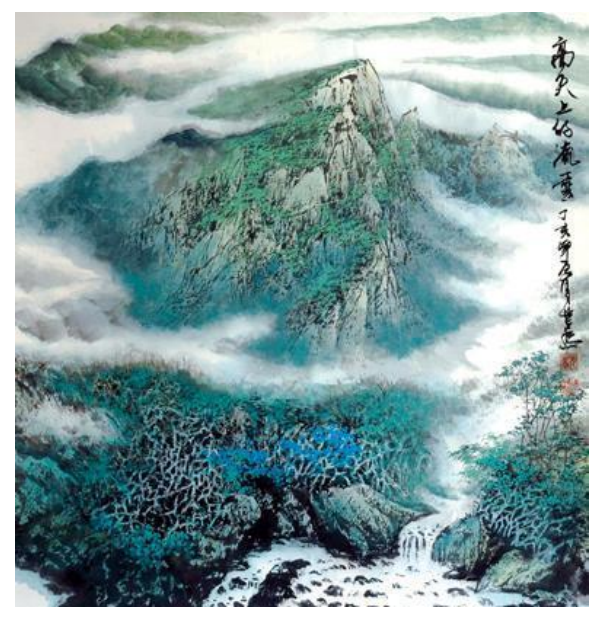

\footnotetext{
${ }^{14}$ See more examples at Shougang Group n.d.(c).
} 
Some explanation of the benefits of engaging in such artistic pursuits, from an employee's perspective, is given in the following excerpt from a lyrical prose piece on calligraphy entitled "Watching the Characters Dance," posted on China Datang Corporation's literary forum (Yang 2007):

When I am not too busy, I like to practice brush calligraphy, and I view calligraphy as an important part of my life. I don't do it to pose as a lover of culture but rather as a way of consoling my sometimes wavering spirit, and ensuring that my spirit does not become hardened or dull ... When the soft brush goes leaping and gliding over the pure white responsive surface of the calligraphic paper, ... my hand races to keep up with my mind's intent, and all my stress, worries, depression and exhaustion melt away and are released amidst the dance of Chinese characters.

Yang Xiuli, the author of this piece, clearly views calligraphy as a kind of therapeutic activity. The corporation gets no mention at all, and in fact - as we saw with the prose piece "Autumn Leaves" above - the author implies that she is using calligraphy as a way to escape from the "stress, worries, depression and exhaustion" of her daily working life.

\section{Praising Exemplary Employees: Members of the "Greater (Corporate) Family"}

If many of the literary and cultural creations published in corporate magazines and online forums show little concern for promoting the firm's business, or encouraging employees to devote themselves to the work of the corporate "family," the final category of content that regularly appears in these magazines tends towards the opposite extreme. Pieces on 
exemplary employees describe, sometimes in mind-numbing detail, how the "employees of the month" displayed intense dedication and put in hours of selfless effort for the sake of the corporation. In this way, they demonstrated "team spirit" (tuandui jingshen) and embodied the ideals of "socialism with Chinese characteristics" and striving for a "harmonious society." The terminology used in these kinds of writings is very similar to that found in editorials in the official Chinese media, and in many cases, the editorial committee within the corporation that produces such content is under the aegis of the corporation's Communist Party Committee or Politics and Ideology Department. It is slightly surprising to find this Communist-style genre still going strong in the capitalistminded new millennium.

Of course, there are some developments in the content of these pieces that set them apart from their Communist-period forerunners. Helping the corporation increase its profits, for example, is no longer seen as suspect political behaviour but is strongly encouraged. And politics now generally takes a distant third place to technical competence and business efficiency. Yet the tone of these pieces and their constant refrain that employees should sacrifice themselves (and their families) for the greater good of the corporate family and the nation bears striking parallels to the selfless revolutionary ardour demanded by the Communist Party in earlier decades.

A couple of examples should make these parallels clearer. China Datang Corporation's online forum entitled "Stories of Dedication" was set up in 2007 (China Datang 2007b). The forum was meant to encourage employees to submit for publication "classic 
examples" of their colleagues" "assiduous struggle" to improve their management and marketing prowess, to promote safety and energy efficiency awareness, and generally to demonstrate the corporation's respect, love and care for "people” (China Datang 2007a). Ideally, the stories should also reveal how employees are working together with the corporation to "broadly shoulder their social responsibilities" and to "build a harmonious corporation and a harmonious society." Employees are encouraged to submit their writings to the corporation's Propaganda Office, and the best pieces will be published on the corporation's website and in a book entitled Our Dedication Stories. Those whose work is published in the book will receive a complimentary copy and manuscript fee. Numerous stories were submitted in response to this call for submissions, with approximately 160 of them posted on the website between April and October 2007 (China Datang 2007b).

The content of these stories contrasts dramatically with the leaf-rustling and calligraphic jotting of the Literary Garden pieces. The authors seem to be competing to prove that their particular subsidiary of the corporate group is the most "assiduous." For example, in a piece entitled "Late Carnations," the author praises Pu Minghai, a deputy production manager of a power generating subsidiary, for working so hard to prepare for the corporation's "safe production month" in mid-2004 that he regularly stayed up till three or four a.m. to finish things off in the office (Qiao 2007). Not only that, he was so busy during this period that he couldn't go back to his parents' rural home to visit them, even after receiving a message that his mother was at death's door and "she would really like to see you if you are not too busy ..." By the time he finally makes it back home, his 
mother is already dead and buried, so he leaves the Mother's Day carnations that he brought for her on her grave instead. His father dies of grief three days later. But does that stop Pu Minghai from returning to work straightaway? No! Because, as he puts it: "I can never let my own personal problems get in the way of the Corporation's important business. My parents would certainly have understood this.” An editorial comment on this piece clearly states the moral:

Putting aside one's small family [i.e. one's blood relations] for the sake of the greater family [i.e. the Corporation] is the spiritual essence of Datang employees. It is only because there are innumerable other Datang employees like Pu Minghai, who are willing to offer their spirits wholeheartedly [to the Corporation], that ... we have ignited the hope of breaking into the top five hundred corporations in the world! (Qiao 2007)

As if to try and top this, a further piece posted two days later describes one Ye Liming, a female supervisor at Datang's Huainan Tianjia'an Power Station (Zheng 2007). During a particularly busy maintenance session, Ye leaves her five-year old daughter sleeping alone at home while she does the night shift for several nights in a row (her husband is also on night shifts). When her remarkably sensible daughter calls to say she is sick, she tells the daughter to "try and find some medicine yourself, and put up with it a bit longer." The next day, when Ye is still at work, having "forgotten about her sick daughter at home" because she is so busy, her mother calls to say that the daughter is now in the hospital diagnosed with a serious case of pneumonia. The daughter had apparently 
realized that Ye had no time to take her to the doctor, so she called her grandmother instead (who was living in a different town), and finally got some medical attention. But even then, Ye still needs to stay at work to test all the generators, so she tells her daughter to stay with her grandmother until all the repairs are completed. The editorial concludes:

We should all admire this devotion to the job and to the workplace family. It is millions of outstanding employees like Ye Liming, sacrificing their "small families" for the good of the "greater family," who make Datang's business so dazzling and glorious! (Zheng 2007)

Of course, all this self-sacrifice (or family and child sacrifice) has the ultimate motive of increasing the corporation's profits. As another employee declares: "The most important thing is to turn the corporation around and make it profitable. The enterprise is like our garden, and its profits are our greatest harvest" (Xu and Lou 2007). Yet these kinds of stories rarely make it clear exactly how corporate profits translate into increased rewards for the individual employees. The main focus appears to be on creating a sense of urgency or constant crisis, so that employees are willing to sacrifice their individual interests for the sake of the collectivity, without necessarily expecting an immediate economic pay-off.

The contrast with the kinds of stories about carefree excursions and relaxing hobbies in Datang's Literary Garden forum could hardly be starker. This suggests that the Stories of Dedication represent only a certain group of extremely ambitious individuals within the 
corporate group, rather than "millions of outstanding employees," and that there are plenty of other employees who for good reasons are not as willing to "offer their spirits wholeheartedly" to the corporation.

Certainly Datang is not unique in promoting its star workaholics as model employees, or in using socialist-style propaganda techniques to encourage employees to work harder for the greater corporate family. The magazine of the privately-managed Zhengtai Group, an electrical instrument manufacturer, approvingly quotes Xu Junyin, one of its Nanjing branch managers: "My favourite pastime is constant work, and apart from that, I also like to work!" The article then continues: "Nanjing people seem to enjoy a leisurely life, but $\mathrm{Xu}$ Junyin has no interest in leisure at all. ... He doesn't have any weekends or any fixed time to get off work at night. His whole world is work" (Wu 2008).

Despite the continuing publication of articles like these, celebrating work for the corporation above everything, there is a growing recognition in the Chinese media and among corporate and government leaders that too much work pressure on employees has harmful and counterproductive consequences. A recent article in the national lifestyle magazine, Xinmin Weekly, raised questions about the high stress environment in China's hi-tech corporations after six young employees of Huawei Technologies died of unnatural causes (including suicide and sudden unexplained seizures) within the space of two years (Anon. 2008). Likewise, the Chinese government recently implemented the PRC Labour Contract Law - over the strenuous objections of many multinational corporations - that attempts to protect employees from the more egregious forms of exploitation by 
employers, such as failing to provide written employment contracts or any kind of job security (Global Labor Strategies 2007).

Faced with such negative publicity and legal pressure, some large Chinese corporations have made purely cosmetic changes, while others have engaged in more serious soul searching. Huawei Technologies, for example, while claiming that employees should no longer be allowed to live and sleep in the office (which was a relatively common practice at the corporation before), and that they should develop other interests besides work in their spare time, at the same time forced 7,000 of its longer-serving employees to resign and re-apply for positions at the firm, so that they would not be eligible for the long-term contracts mandated to employees who have served for over ten years under the Labour Contract Law (Jiang and Li 2007; Anon. 2007b). Huawei justified this controversial move by arguing that the firm simply could not motivate its longer-serving employees to keep improving their performance if they didn't have the "flexibility" to let them go in the future (Anon. 2007c). The underlying message to Huawei’s employees is clear: if you don’t keep working like hungry wolves, you will lose your job. ${ }^{15}$

By contrast, another privately-managed conglomerate, the Tongwei Group, recently published in its online magazine a remarkably candid and thoughtful article on the harmful effects of overwork, and proposed concrete measures to deal with them (Jin 2007). The article begins by noting the recent deaths at Huawei and other corporations, and the growing realization that overwork can lead to death, in some cases, and more commonly, that there is a clear link between work pressures and various kinds of chronic

\footnotetext{
${ }^{15}$ For Huawei’s “wolf culture," see note 13 above.
} 
illnesses. The author then notes that within Tongwei itself, it is quite common even for younger employees in the 20-30 year-old group to find themselves suffering from various ailments, despite having worked at Tongwei for only one year. And for certain high stress positions, such as managerial and sales staff, the incidence of more serious medical problems is particularly frequent: more than $80 \%$ "felt physically and mentally exhausted," and among these, 40\% were undergoing treatment for conditions such as alcoholic liver, fatty liver, and chronic neck and shoulder pain, while 50\% reported suffering from insomnia. The majority of employees also had to live apart from their families - either because they could not afford housing close to their work, and therefore lived in communal dormitories, or because their job required frequent extended stays in other regions or countries. This added another layer of stress to their lives.

The article then proposes measures that both the corporation and employees should take to improve this dire situation, such as an "employee assistance program" to identify and help all employees with physical or emotional problems caused by work stress. This will benefit the "sustainable development" of the firm itself, and will be a "win-win situation for employees and the corporation" (Jin 2007).

As for employees, they also need to recognize that they can look after their health more carefully. They shouldn't allow work to take over their lives, but should make sure that regular exercise and a reasonable amount of leisure time with their families take precedence over everything else. After all, the pressure often comes from employees' fear 
or their desire to make more money rather than directly from their corporate supervisors. As one Tongwei employee puts it:

In an environment and society like China, where the population is large, land is scarce, and resources are limited, where everyone is looking for short-term profits, it will be hard to change things quickly. All we can do is try to ... be slightly less impetuous and more calm; ... slightly less focused on results and more focused on the way we get there (Jin 2007)

This comment, although ostensibly about reducing employee stress, seems to sum up nicely one of the main reasons for corporations to publish in-house magazines and to encourage their employees to produce creative work for those magazines - namely, to help employees develop other interests and release tensions built up at work. But in a complex organization like a large business corporation, there is bound to be more than one explanation as to why corporate magazines have become so popular in China, and what functions they serve or are intended by different groups within the corporation to serve. In the concluding section, I will analyze this question in some detail.

\section{Conclusion: Contradictory or Complementary Functions of Chinese Corporate Magazines?}

Clearly a primary function of corporate magazines throughout the world is propaganda or self-promotion: in other words, spreading news of the corporation's achievements to the 
outside world and to its own employees. Chinese corporate magazines are no different with their glowing reports on the firm's business operations and future growth prospects. In the case of large corporate groups, with divisions and subsidiaries all over China and abroad, the corporate magazine also creates a sense of solidarity among employees in different places, and an appreciation of what the other divisions of the firm are up to.

Yet Chinese corporate magazines seem to go much further than this, with their encouragement to employees to contribute articles and other creative work that do not necessarily have a direct connection to the company's business. Though it is impossible to generalize about foreign (i.e. non-Chinese) corporate magazines, one standard manual for internal corporate communication sets out the following list of content that British employees are typically interested in: Organizational plans for the future; Job advancement opportunities; Job-related how-to information; Productivity improvements; Personnel policies and practices; How we're doing versus the competition; How my job fits into the organization; How external events may affect my job; How profits are used; and Financial results (Smith and Mounter 2005, 123). These are all solidly practical issues, far removed from the cultural content that regularly appears in Chinese corporate magazines.

Certainly, one could view many of the articles and artwork contributed by employees to Chinese in-house magazines as a kind of corporate propaganda. Some of these contributions directly promote the firm's slogans and stated values, while others without such a clear corporate message can still demonstrate to the wider society that the firm's 
employees are well-rounded and cultivated human beings, not simply money-grabbing automatons. Indeed, in recent years, the Chinese government has started to require large state-controlled corporations to "improve" their corporate culture, and one major aspect of the official definition of corporate culture is that:

[Firms] must use innovative methods for building corporate culture ... especially through new media such as internet sites, in-house corporate publications, broadcasts and cable TV, providing healthy and beneficial cultural products to raise the cultural level of employees and expanding the effectiveness of corporate culture promotion. They must focus on guiding and strengthening non-work group cultural activities such as photography, calligraphy, art, literature and sports, and they must organize a wide variety of other healthy and distinctive non-work cultural activities in which everyone can participate ... in order to satisfy employees' spiritual and cultural thirst for knowledge, beauty and pleasure (SASAC 2005, article 8). ${ }^{16}$

Corporate magazines and online forums are an excellent way for firms to prove to the government that they are addressing this culture requirement.

Some corporations make the propaganda or values promotion function explicit when introducing their magazines. For example, in 2005, Huawei Technologies published an article about its culture that included the following description:

\footnotetext{
${ }^{16}$ For further analysis of this important policy document, see Hawes 2008, 40-2.
} 
At Huawei, you will see a newspaper called Huawei People. This paper, which is required reading for all Huawei employees, is not just an information source. It's so important and has such a deep impact on employees, that it is actually the frontline for spreading Huawei’s culture (Zhao 2005).

So an extension of the propaganda function is the idea that getting employees to read and contribute to these in-house magazines will help them to understand, accept and spread the firm's values. And the magazine or forum has a reinforcing effect when employees start to act as the mouthpiece for these values.

Of course, the values of one corporation may differ from those of other corporations. Thus, where China Datang's online forum rams home the value of sacrificing one's smaller family for the greater corporate family, Tongwei's magazine makes it clear that overwork and separation from family lead to chronic health problems and should be discouraged.

More broadly, many Chinese corporate magazines also appear to serve a more personal social or spiritual function for employees. As noted in Tongwei's magazine, large numbers of employees in major Chinese corporations are living away from their families for extended periods. A lot of the larger companies have grown from virtually nothing in a couple of decades. They've recruited thousands of new employees, and most of these employees are young and come from other parts of the province or country, and they live in company dormitories or apartments. So the company becomes their new home, and 
they expect the company to create a community so that they can get to know their colleagues and feel they belong there. This context helps to explain the prevalence of “chicken soup for the soul"-type inspirational and self-help articles, as well as the more reflective cultural and human interest pieces that I quoted above. Reading such articles may help employees to deal with some of the stresses of their work lives, and reminds them that they have a forum to share their experiences with like-minded colleagues in the firm.

Of course, encouraging employees to express themselves freely could be risky for the corporation. On the positive side, self-expression may allow employees to release tension and feel as if their lives have meaning beyond the daily grind of work. But if employees publish articles that are too negative in tone, it may result in a general questioning among their colleagues as to why they are wasting their youth trying to raise the profitability of the firm by one or two percentage points. Possibly the strong guidance on content that China Datang's editorial committee gave to its employees when urging them to submit Stories of Dedication was designed to counter the kind of negative attitudes to work that were emerging in the corporation's Literary Garden forum. Still, if corporations are too heavy handed in imposing editorial guidelines on employees, they will end up with plenty of vapid propaganda but their magazines will lose their appeal to most of their employee readers, and hence their emotional resonance and impact. In the case of China Datang, it is interesting that the firm's Literary Garden forum is still flourishing today, even after running for three years, whereas the much more gung-ho and jingoistic Stories of Dedication ran for only a few months after its call for submissions. 
Perhaps within a large corporate group there will inevitably be contrasting sets of values - some even mutually inconsistent - and if employees are allowed to express themselves publicly, these contrasts will emerge in the firm's various publications. If enough employees express opinions that dissent, even indirectly, from the dominant firm ideology, at some point the firm's management may become aware of the problem and address it, as in the case of Tongwei's articles on the issue of employee overwork. In this way, the corporate magazine or forum can become a vehicle for employees to make management aware of their concerns and frustrations, yet without necessarily engaging in direct confrontations with management that would result in people losing face. ${ }^{17}$

A final function of these corporate magazines is as an integral component of the educational programs that most large Chinese firms have established. Recognizing that many lower-level employees may not have attended college or even completed high school, many firms offer both technical and broader cultural literacy training, often in socalled corporate universities. ${ }^{18}$ Employees who pass these courses are more likely to gain promotion, as their "quality" will have improved. The idea of raising employees' quality through broad-based in-house educational programs is not a new one in China. It appears to have roots in Confucian ideals about the employer's duty to cultivate employees, and was already prevalent among business firms in the Republican period, as Wen-hsin Yeh has shown (Yeh 1995, 107-8). But it is interesting to see the corporate magazine being

\footnotetext{
${ }^{17}$ China Datang has another forum entitled "Datang wangtan" [Datang Network Talk] that seems to fulfil this function: employees post their opinions on various aspects of company operations, many suggesting improvements based on the experiences of the group's subsidiaries (China Datang n.d.(a)).

${ }^{18}$ The most famous example in China is the Haier Group's Haier University, which offers programs in management, corporate culture, strategy, internationalization, and so on (Haier University n.d.).
} 
used as a vehicle to display the successful results of these programs. Employee "students" are encouraged to publish their written and creative work in the magazines, thereby gaining an immediate captive readership and a sense of achievement. At the same time, the magazines also contain articles reporting on the benefits of these educational programs for employees' career development, or for their personal sense of well-being.

One such report, posted on the website of the Zhengtai Group, describes a "cultural salon" where three employees who had benefited from part-time study programs encourage a group of production-line workers to get involved in these programs too $(\mathrm{Li}$ 2005). One of the three, a female employee, Chen Minmei, recalls that four years earlier when she joined Zhengtai, she only had a middle school education, but through conscientious study, she gradually "improved her work quality, her cultural level, and her writing skills." Eventually, she was promoted to the position of verification clerk and was accepted as a student at Zhejiang Academy of Science and Technology. She had also written many articles for Zhengtai News, the company's in-house magazine, and won an award as "outstanding correspondent of the year" for the magazine. She managed to get her writings published in various other newspapers and magazines as well. The host of the salon concludes with some purple prose: "Self-improvement is never-ending, like climbing a high mountain. Let us follow Zhengtai, and Nan [Cunhui] our Chairman, to test our strength by climbing that mountain, struggling uphill. We may never reach the top, but we can always keep going higher!” (Li 2005) 
The varying functions of the magazines that I have described reflect contemporary Chinese corporations' attempt to create a new identity for themselves within a rapidly transforming society. In order to satisfy various stakeholders, this identity must somehow combine elements of modern business practices, a focus on profits, and rational management, with promotion of traditional Chinese cultural values, plus a dose of socialist communal spirit. Certainly corporations in every society must seek to balance the sometimes contradictory demands of those inside and outside the corporate walls. Yet in China, there is a special emphasis on raising employees' educational and cultural level and on the idea that the corporation can be a site for self-improvement rather than simply a workplace. Though some firms may trumpet this idea in their promotional materials without actually giving employees time and space to develop themselves, the sheer quantity and quality of much of the creative work by employees found in corporate magazines suggests that many Chinese corporations really are seeking a balancing point between economic imperatives and employee self-realization. It remains to be seen whether this effort will lead to better-performing businesses and more motivated employees in the long term, but in the meantime, it certainly makes for very interesting reading on Chinese corporate websites. 


\section{Bibliography}

Anon. 2008. Miwu zhong de Huawei zishamen: dang langxing chengwei yi zhong wenhua. Xinmin zhoukan, 2 April.

Anon. 2007(a). Daochu na yi li sha. Cosun People 79. Posted 17 July at http://www.qiaoxing.net/culture/cosunhr.asp?sclass=32. Accessed 1 September 2008.

Anon. 2007(b). Huawei cizhi fengbo yu lao yuangong de hetong weiji. Xinhuanet, 5 November, at http://news.xinhuanet.com/employment/200711/05/content_7012267.htm. Accessed 1 September 2008.

Anon. 2007(c). Zhuizong baodao: Huawei fouren guibi Laodongfa. Xinhuanet, 5 November, at http://news.xinhuanet.com/employment/2007$\underline{11 / 05 / \text { content 7012305.htm. Accessed 1 September } 2008 .}$.

China Datang Corporation. 2007a. Guanyu jinyibu zhengji qiye wenhua gushi de tongzhi. Posted 23 April, at http://www.chinacdt.com/enterpriseculture/culturenavigate/641985.html. Accessed 1 September 2008.

China Datang Corporation. 2007b. Tongxin gushi. Forum at http://www.chinacdt.com/enterpriseculture/tongxinstory/index.html. Accessed 1 September 2008.

China Datang Corporation. N.d.(a). Datang wangtan. Forum at http://www.chinacdt.com/news/networktalk/index.html. Accessed 1 September 2008.

China Datang Corporation. N.d.(b). Tangyun wenyuan. Forum at http://www.chinacdt.com/enterpriseculture/literature/index.html. Accessed 1 September 2008.

China Datang Corporation. N.d.(c). Zong jingli zhici. Posted at http://www.chinacdt.com/aboutdatang/deliverspeech/1067.html. Accessed 1 September 2008.

COFCO Group. n.d.(a). Qiye Zhongliang online, at http://cofcomag.cofco.com/cn/periodical/old.aspx. Accessed 1 September 2008.

COFCO Group. n.d.(b). Women de yewu. Posted at http://www.cofco.com/cn/industry/index.aspx. Accessed 1 September 2008.

COFCO Group. 2008. Qiye Zhongliang 31, No.2. Posted at http://cofcomag.cofco.com/cn/periodical/index.aspx?con_id=1594. Accessed 1 September 2008.

Cosun Group. N.d.(a). Cosun People online, at http://www.qiaoxing.net/culture/culture05.asp. Accessed 1 September 2008. 
Cosun Group. N.d.(b). Jituan jianjie. Posted at http://www.qiaoxing.net/profile/profile01.asp. Accessed 1 September 2008.

Gao Kai. 2007. Qiu ye. Posted 29 October, at http://www.chinacdt.com/enterpriseculture/literature/1198776.html. Accessed 1 September 2008.

Global Labor Strategies. 2007. Undue Influence: Corporations Gain Ground in Battle over China's New Labor Law. March. Online at http://laborstrategies.blogs.com/global_labor_strategies/files/undue_influence_glob al_labor_strategies.pdf. Accessed 1 September 2008.

Haier Group. N.d. Haier ren shuhua. Forum at http://www.haier.cn/about/culture_workforce.shtml. Accessed 1 September 2008.

Haier University. N.d. Haier daxue. Website at http://www.haier.cn/about/university_index.shtml. Accessed 1 September 2008.

Hawes, Colin. 2008. "Representing Corporate Culture in China: Official, Academic and Corporate Perspectives," The China Journal 59 (January): 31-60.

Huawei Technologies. 2006a. Chanwu guanli. Huawei People 179 (August). Posted at http://www.huawei.com/cn/publications/view.do?id=1112\&cid=1222\&pid=87. Accessed 1 September 2008.

Jiang Qiang and Li Yuan. 2007. Huawei buchang shiyi yuan guli qiqian ming lao yuangong cizhi. Originally from Nanfang dushibao, posted on Xinhuanet (2 November) at http://news.xinhuanet.com/employment/200711/02/content_6996878.htm. Accessed 1 September 2008.

Jin Se. 2007. Jujue touzhi: bu rang yali zhuzai jiankang. Tongwei Lifestyle, posted 30 December, at http://www.tongweinews.com/zine/Show.xf?ID=6860. Accessed 1 September 2008.

Kirby, William C. 1995. China Unincorporated: Company Law and Business Enterprise in Twentieth Century China. Journal of Asian Studies 54.1 (February): 43-63.

Landsberger, Stefan. 1995. Chinese Propaganda Posters: From Revolution to Modernization. Amsterdam: Pepin Press.

Li Jiagui. 2005. The Cultural Salon Goes Down to the Production Line. Posted 1 July on Zhengtai's website but no longer accessible. Copy on file with author.

Liu Guangxia. 2007. Yi gen cong li de aiqing. Posted 17 October at http://www.chinacdt.com/enterpriseculture/literature/1014301.html. Accessed 1 September 2008. 
Liu Ruifu. 1998. Zhongguo gongsi fa. Beijing: Falu chubanshe.

Minying jingji xinxiwang. 2005. Zhongguo minying qiye 500 qiang mingdan quanlu http://www.gdcei.com/news_detail.php?id=822\&nowmenuid=30\&cpath=0088:\&ca $\underline{\text { tid=88. }}$. Accessed 1 August 2006. Copy on file with author.

Qiao Mu. 2007. Chilai de kangnaixin. Posted 24 September at http://www.chinacdt.com/enterpriseculture/tongxinstory/1100465.html. Accessed 1 September 2008.

Shougang Group. N.d.(a). Baoshe jianjie. Posted at http://www.sgdaily.com/Templets/简 介.htm. Accessed 1 September 2008.

Shougang Group. N.d.(b). Xinwen yewu yanjiu. Posted at http://www.sgdaily.com/Html/xwywyj/index.html. Accessed 1 September 2008.

Shougang Group. N.d.(c). Zhigong shuhua shying. Posted at http://www.sgdaily.com/Html/shsy/index.html. Accessed 1 September 2008.

Sinopec Group. N.d.(a). Zhongguo shihua xinwenwang lianxi fangshi. http://www.sinopecnews.com.cn/shnews/2007-03/09/content 428199.htm. Accessed 1 September 2008.

Smith, Lyn and Pamela Mounter. 2005. Effective Internal Communication. London: Chartered Institute of Public Relations \& Kogan Page.

State-owned Assets Supervision and Administration Commission of the State Council (SASAC). 2005. Guanyu jiaqiang zhongyang qiye qiye wenhua jianshe de zhidao yijian. 16 March. Posted at http://www.sasac.gov.cn/gzjg/xcgz/200504190137.htm. Accessed 1 September 2008.

Tomasic, Roman, Stephen Bottomley and Rob McQueen. 2002. Corporations Law in Australia. Sydney: Federation Press.

Tongwei Group. N.d. Tongwei Lifestyle online at http://www.tongweinews.com/channel/5/aboutus/showclass.xf?ClassID=77. Accessed 1 September 2008.

Wang Guoshun. 2008. Yougu liuyun. Posted July 9 at http://www.sgdaily.com/Html/shsy/2008-7/9/091348805.html. Accessed 1 September 2008.

Wang Yongde. 2007. Langxing guanli zai Huawei. Wuhan University Press.

Wu Gaoyi. 2008. Xu Junyin: shengming zhanfang zai gudu Jinling. Zhengtai Magazine (February). Posted at http://www.chint.com/staging/newsCenter/chintnewspaper.jsp?rootfldr_id=6\&subfl 
$\underline{\mathrm{dr} \_\mathrm{id}=32 \& \text { thirdfldr } \_\mathrm{id}=641 \& \mathrm{fldr} \_\mathrm{id}=643 \& \text { mon } \_\mathrm{id}=645}$. Accessed 1 September 2008.

Xiao Difei et al, eds. 1983. Tang shi jianshang cidian. Shanghai cishu chubanshe.

Xu Jianhua and Lou Peitao. 2007. Wuye dianhua. Posted 25 September at http://www.china-cdt.com/enterpriseculture/tongxinstory/1107797.html. Accessed 1 September 2008.

Yang Xiuli. 2007. Kan wenzi tiaowu. Posted 24 September at http://www.chinacdt.com/enterpriseculture/literature/938496.html. Accessed 1 September 2008.

Wen-Hsin Yeh. 1995. Corporate Space, Communal Time: Everyday Life in Shanghai's Bank of China. The American Historical Review 100.1 (February): 97-122.

Zhao Jijun. 2005. Ganwu Huawei wenhua. Huawei People 164 (June). Posted at http://www.huawei.com/cn/publications/view.do?id=86\&cid=90\&pid=87. Accessed 1 September 2008.

Zhengtai Group. N.d. Zhengtai News and Zhengtai Magazine at http://www.chint.com/staging/newsCenter/chintnewspaper.jsp?rootfldr_id=6\&subfl

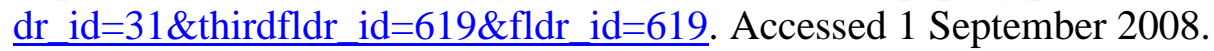

Zheng Yiping. 2007. Mama, ni zaodian huilai! Posted 26 September at http://www.chinacdt.com/enterpriseculture/tongxinstory/1110687.html. Accessed 1 September 2008.

Zheng Zhengmin. 2008. Jingming de shichang xiaoshou guanli. Enterprise COFCO 31 (February). Posted at http://cofcomag.cofco.com/cn/periodical/index.aspx?con_id=1594. Accessed 1 September 2008. 